\title{
From Aid to Community Empowerment: Food security as a political project
}

\section{SID}

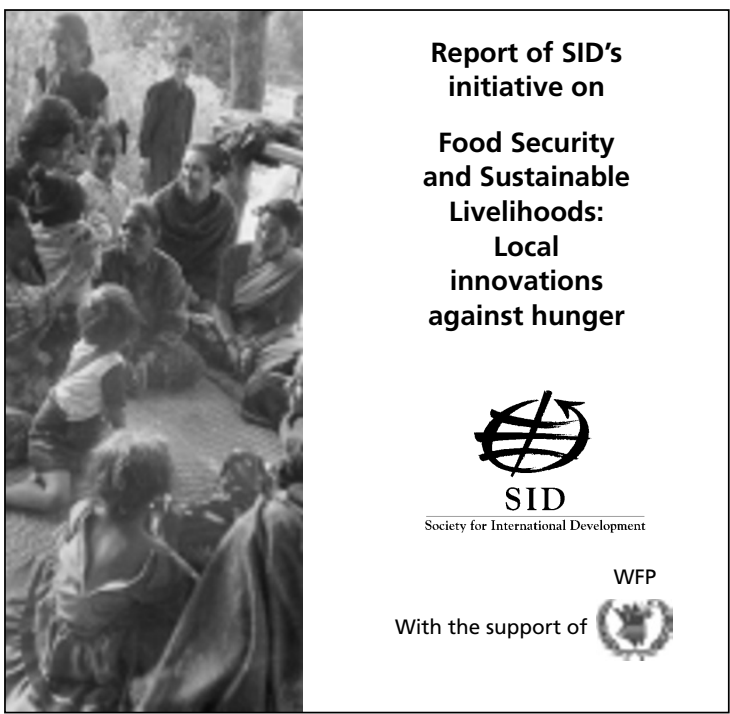

Three thousand people in 28 countries of the South, through 35 national and sub-national workshops as part of the Society for International Development's initiative on 'Food Security and Sustainable Livelihoods', agreed that:

- Democracy is a must to achieve food security: economic and social democracy, political democracy, and also new forms of international solidarity to support national democratization processes.

- There is no follow-up on the ground of the commitment made in the World Food Summit 'to mobilize all stakeholders at all levels of society and their resources in each country, in support of the implementation of the World Food Summit Plan of Action'.

\section{Priority actions}

\section{Economic and social democracy}

More equitable distribution of and access to land, forests and water

Recognition of the link between food, ecology and culture

Acknowledgement of women's role in food security

Counter the cultural crisis affecting rural communities

\section{Political democracy}

Devolution of power to local communities

Establishment of permanent mechanisms of dialogue between civil society stakeholders and national food security institutions

\section{International solidarity in support of democratic processes}

It is crucial that initiatives of development co-operation - including food for development programmes - support sustainable livelihoods, foster processes of collective empowerment and promote partnerships among all stakeholders.

Please contact the SID Secretariat for a copy of the report and/or a CD Rom with details and information on country processes. See SID website $<$ http://www.sidint.org> 